\title{
Tahap Perancangan Pengajaran Menerusi Pengintergrasian Kemahiran Berfikir Aras Tinggi (KBAT) di Dalam Mata Pelajaran Pendidikan Islam Sekolah Rendah Malaysia
}

\author{
Mohd Syaubari Othman ${ }^{1 *}$, Ahmad Yunus Kassim² \\ ${ }^{1}$ Academy of Contemporary Islamic Studies, \\ Universiti Teknologi MARA, 40450 Shah Alam, Malaysia \\ ${ }^{1,2}$ Fakulti Sains Kemanusiaan, Universiti Pendidikan Sultan Idris, Tanjung \\ Malim, Perak \\ *Pengarang Penghubung \\ syaubari@gmail.com
}

\begin{abstract}
ABSTRAK
Kajian ini bertujuan untuk menyelidik perancangan pengajaran guru Pendidikan Islam sekolah rendah menerusi pengintegrasian Kemahiran Berfikir Aras Tinggi (KBAT). Kajian ini melibatkan guru-guru Pendidikan Islam di Malaysia. Komponen berfikir aras tinggi seperti kemahiran banding beza, kemahiran menyusun urutan, kemahiran membuat ramalan, kemahiran membuat definisi dan kemahiran mencipta analogi yang di lihat dalam tiga komponen utama perancangan pengajaran guru iaitu perancangan pendokumentasian, perancangan dari segi komitmen guru dan perancangan pelaksanaan dipilih sebagai kerangka konseptual kajian. Kajian ini menggunakan analisis deskriptif menerusi instrumen soal selidik. Kesemua instrumen pengutipan data ini dibina oleh pengkaji dengan pengubahsuaian daripada instrument KBAT Kementerian Pendidikan Malaysia dan pakar yang terlibat serta kandungannya disahkan oleh panel rujukan pakar. Tahap nilai kebolehpercayaan alpha Cronbach yang diperoleh adalah tinggi iaitu 0.82173 . Seramai 402 orang guru pendidikan Islam dipilih secara rawak mudah untuk menjawab instrumen soal selidik. Data kajian di analisis secara deskriptif menggunakan frenkuensi dan min serta sisihan piawai. Secara keseluruhannya, hasil kajian mendapati amalan perancangan pengajaran di dalam mengintergrasikan Kemahiran Berfikir Aras Tinggi (KBAT) adalah sederhana tinggi $(\min =3.84)$ berdasarkan perancangan komitmen $(\mathrm{min}=$ 3.95), perancangan pendokumentasian $(\min =3.93)$ dan perancangan pelaksanaan $(\min =3.65)$. Implikasi dan cadangan yang dikemukakan dapat memberi gambaran yang bermanfaat kepada kementerian, sekolah, guru dan masyarakat bagi mempertingkatkan tahap amalan pengajaran guru Pendidikan Islam berdasarkan Kemahiran Berfikir Aras Tinggi (KBAT) seperti yang
\end{abstract}


dihasratkan menerusi Pelan Pembangunan Pendidikan Malaysia (PPPM) 20132025.

Kata Kunci: Perancangan Pengajaran, Guru Pendidikan Islam, KBAT, Sekolah Rendah

\begin{abstract}
The purpose of this study is to examine the teaching plan of primary school Islamic teachers through the integration of Higher Order Thinking Skills (HOTS). The study involved teachers of Islamic education in Malaysia. Highlevel thinking components such as differentiating skills, ordering skills, predictive skills, defining skills and creating anology which are seen in three main components of teacher teaching plan i.e documentation, teachers' commitment and implementation were selected as conceptual framework for the study. This study employed descriptive method to analyse the collected data. Data collection instrument for the study was a modified version of HOTS instrument of the Ministry of Education Malaysia. Views and feedbacks from the experts were sought for them to certify the content and constructs of the instrument. The internal consistency of the instrument is good as the value of Cronbach's alpha is high (0.82173). A total of 402 Islamic education teachers were randomly selected to answer the questionnaires. The collected data were then analysed descriptively using frequency, percentages and mean. In overall, the study found that the practice of teaching plan in integrating HOTS is at moderately high level with the overall mean of 3.84 based on commitments planning mean of 3.95, documentation planning mean of 3.93 and implementation planning mean of 3.65. This study finding could provide useful insights to ministries, schools, teachers and communities in enhancing the level of teachers' teaching practice based on HOTS as envisaged in the 2013-2025 Education Development Plan.
\end{abstract}

Keywords: Teaching Planning, Practice of Islamic Education Teacher, HOTS, Primary School

\title{
1. Pengenalan
}

Kemahiran Berfikir Aras Tinggi (KBAT) adalah kemahiran yang memerlukan pengorganisasian pemikiran berdasarkan keupayaan untuk menghurai, menterjemah, mencipta, merefleksi dan menghubungkaitkan sesuatu dengan situasi semasa. Penekanan KBAT ini dalam sistem pendidikan negara adalah lanjutan daripada pelaksanaan kemahiran berfikir secara kritis dan kreatif (KBKK) yang telah dilaksanakan semenjak 1993. Proses pelaksanaan KBAT di Malaysia adalah 
bersumberkan taksonomi bloom dan diubahsuai oleh Lorin Anderson menerusi empat heirarki teratas iaitu mengaplikasi, menganalisis, menilai dan mencipta (Khairiah, 2013; KPM, 2014).

Transformasi kurikulum pendidikan dalam Pelan Pembangunan Pendidikan Malaysia (PPPM) 2013-2025 memberi penekanan utama terhadap konsep KBAT yang berupaya melahirkan generasi yang berkeupayaan dalam pemikiran kritis dan kreatif. Pendekatan ini diperkenalkan untuk mencapai matlamat utama pendidikan iaitu menghasilkan lebih ramai pelajar yang mempunyai keupayaan kognitif aras tinggi melalui pedagogi secara pembelajaran aktif di dalam pengajaran dan pembelajaran. Namun, matlamat ini masih belum tercapai secara sepenuhnya. Justeru, pelbagai pendekatan telah diperkenalkan untuk menghasilkan modal insan yang cerdas, kreatif dan inovatif bagi memenuhi cabaran abad ke-21 agar negara mampu bersaing di persada dunia. Menurut (Amabile M, Hennessey A, Beth. \& Teressa, 2010).

Jika inginkan pelajar yang berpotensi untuk berfikir dan mampu menyelesaikan masalah kita perlu mula menyediakan tugasan-tugasan kompleks yang berkognitif tinggi.

Pengertian ini bertepatan dengan penekanan dalam Islam di mana keupayaan akal merupakan elemen utama dalam pembentukan pelajar yang bersifat holistik iaitu keseimbangan di antara kecemerlangan akademik dan kemantapan sahsiah. Islam menekankan penggunaan akal yang optimun sejak beratus tahun dahulu sebelum barat memperkenalkan, namun ianya tidak digarap dan ditranformasikan sehingga memperlihatkan bahawa ilmuan barat yang meneroka pemikiran aras tinggi ini.

Ini dibuktikan menerusi kekerapan ayat suci al-Quran yang membahaskan berkaitan akal di lebih daripada 45 ayat sama ada dalam bentuk mufrad atau jamak. (Sidek Baba, 2011; Mohd Fauzi \& Mohd Khairul Naim, 2012). Dalam konteks yang sama, Muaz Bin Jabal ketika ditanya oleh Rasulullah s.a.w:

Bagaimana engkau akan memutuskan hukum jika ditanyakan perkara kepadamu?" Mu'adz menjawab, "Saya akan memutuskan perkara itu sesuai dengan hukum Allah (Kitabullah). Apabila aku tidak menjumpai di dalam Kitabullah, aku akan memutuskan dengan Sunnah Rasulullah, saya akan melakukan ijtihad dengan kemampuanku. (Abd Karim Zaidan, 2006).

Maka proses tranformasi Pendidikan Islam telah dirangka berdasarkan pelaksanaan pengajaran guru di sekolah melalui 
pengubahsuaian melibatkan komponen keupayaan kurikulum, pembentukan budaya sekolah, penambahbaikan pengetahuan guru dan tahap kemampuan pelajar mengaplikasi setiap isi kandungan pembelajaran yang diperolehi agar matlamat pengenalan $\mathrm{PdP}$ berorentasikan KBAT dapat dilaksanakan dengan berkesan dan seterusnya membentuk penghayatan akidah yang mantap di kalangan pelajar.(Noor Hisham, 2011; Zuraidah, 2013).

Masyarakat dunia mempercayai bahawa pengetahuan dan kemahiran sangat diperlukan oleh pelajar dalam menghadapi cabaran di abad ke-21. Walaupun terdapat perbezaan dari segi maksud terminalogi kemahiran abad ke-21 (21 st century skills) di antara negara-negara di dunia, namun kesemuanya memberi penekanan terhadap pengetahuan, kemahiran dan nilai (Saavedra \& Opfer, 2012). Selain itu, laporan yang dikeluarkan oleh Perunding Kestrel Education daripada England dan $21^{\text {st }}$ Century School daripada Amerika Syarikat pada 2011 menyatakan bahawa pemikiran aras tinggi dalam kalangan guru dan pelajar di Malaysia masih rendah. Berdasarkan kajian yang dilaksanakan, guru yang melaksanakan pengajaran yang mengandungi pedagogi berdasarkan kemahiran berfikir aras tinggi (KBAT) berupaya untuk meningkatkan kefahaman dan perubahan di dalam amalan perlakuan pelajarnya (Boaler, 2008; Siti Marlina, 2013; KPM, 2014).

Dapatan ini seiring dengan pemantauan laporan kebangsaan (Jemaah Nazir dan Jaminan Kualiti, 2011) bagi mata pelajaran pendidikan Islam (pemeriksaan khas KBAT) melibatkan 103 sekolah rendah dengan 228 pencerapan $\mathrm{PdP}$ mendapati $41.92 \%$ pelajar tidak dilibatkan di dalam aktiviti berkumpulan, $43.73 \%$ pelajar tidak menguasai objektif seperti yang ditetapkan dan $49.47 \%$ pelajar gagal mematuhi prosedur di dalam standard melaksanakan latihan.

Bagi kualiti pengajaran guru, perancangan PdP ditulis secara umum dan kurang menjurus kepada pernyataan bentuk perlakuan yang boleh diukur, $34.01 \%$ gagal menyampaikan isi kandungan pengajaran dengan baik, $47.58 \%$ menggunakan sumber pendidikan namun hanya bersifat tradisional seperti manila kad dan lembaran kerja, kurang menggunakan peralatan berorentasikan teknologi maklumat dan $55.82 \%$ soalan yang dikemukakan oleh guru dapat meningkatkan pengetahuan baru, namun hasil penilaian penyoalan kurang dimanfaatkan untuk tindakan susulan sama ada dalam bentuk pemulihan dan pengayaan. Keseluruhannya menerusi laporan di paparkan kelemahan perancangan guru yang menghasilkan kualiti pengajaran guru pendidikan Islam masih berada di 
tahap sederhana dan ini memerlukan pelaksanaan beberapa penambaikan bagi mencapai tahap baik dan cemerlang.

Selain itu, berdasarkan kajian yang dilakukan oleh Ab Halim dan Nik Mohd Rahimi (2011) dalam kajian mereka terhadap 89 pelajar yang ditemubual dan melakukan pemerhatian di negeri Selangor, Perak dan Terengganu mendapati bahawa kaedah pengajaran guru yang tiada perancangan menyebabkan kaedah kuliah dan penerangan telah digunakan sebagai medium utama pengajaran pendidikan Islam. Ini bererti kepentingan perancangan di dalam pengajaran dan pembelajaran pendidikan Islam perlu difahami seterusnya diaplikasi bagi memastikan ianya tidak menjejaskan tahap kefahaman pelajar. Kajian mereka juga mendapati asas perancangan pengajaran adalah antara elemen penting dalam menentukan keberkesanan pengajaran.

Kajian ini disokong oleh kajian Wan Hassan, Sulaiman Shakib, Zulkiflee dan Mohd Nasir (2013) yang mendapati guru-guru pendidikan Islam tidak merancang penggunaan bahan bantu mengajar (BBM) di dalam perancangan pengajaran dan lebih memberi tumpuan kepada kaedah penerangan sahaja. Ini bertentangan dengan amalan pengajaran KBAT yang mengkehendaki BBM digunakan secara optimum khususnya di tahap perancangan pengajaran bagi menjelaskan sesuatu permasalahan terutama yang sepatutnya menggunakan tayangan video, internet interaktif dan jaringan maya.

Justeru, kajian ini dijalankan bagi mengenalpasti tahap perancangan pendokumentasian pengajaran GPI berdasarkan KBAT dalam mata pelajaran pendidikan Islam sekolah rendah, mengenalpasti tahap perancangan komitmen guru berdasarkan KBAT dalam mata pelajaran pendidikan Islam sekolah rendah, juga mengenalpasti tahap perancangan pelaksanaan berdasarkan KBAT dalam mata pelajaran pendidikan Islam sekolah rendah.

\section{Sorotan Literatur}

\subsection{Perancangan Pengajaran}

Perancangan pengajaran adalah peringkat berdasarkan teori yang dibangunkan oleh (Al-Qabisi, 1955; Robert Glaser, 1983; Ibn Khaldun, 1993) merangkumi elemen perancangan komitmen, perancangan pendokumentasian dan perancangan pelaksanaan. 


\subsubsection{Perancangan Pendokumentasian}

Strategi pengajaran adalah lebih penting sekiranya guru mengajar pelajarpelajar yang mempunyai kebolehan, pencapaian, kecenderungan serta minat yang pelbagai. Guru seharusnya merancang berasaskan dokumen sebagai panduan khususnya kaedah yang digunakan untuk mengajar kumpulan-kumpulan pelajar yang pelbagai aras kognitif (Kamarul Azmi et al., 2010).

Contohnya, dalam bilik darjah KSSR yang biasanya terdiri daripada kumpulan pelajar-pelajar yang lemah, sederhana serta yang cemerlang. Guru terpaksa memikirkan strategi pengajaran yang terdiri daripada pelbagai kaedah mengajar untuk memenuhi keperluan semua kumpulan. Untuk itu, jalinan dokumen merupakan rujukan bagi membentuk aliran pola pemikiran pelajar dan diterjemahkan menerusi pelaksanaan yang bersesuian (Siti Marlina, 2013).

Di samping itu, setiap bilik darjah mempunyai halangan serta rintangan-rintangan yang tersendiri seperti keadaan fizikal, kemudahan bilik darjah, nilai, sikap serta latar belakang sekolah dan pelajar. Lantaran itu, seseorang guru bukan sahaja mesti menguasai pelbagai kaedah mengajar tetapi yang lebih penting adalah bagaimana mengintegrasikan serta menyusun kaedah-kaedah itu dalam bentuk dokumen berdasarkan tempoh masa yang ditetapkan agar menghasilkan keberkesanan dalam strategi pengajaran yang digunakan (Ab Halim et al., 2007, 2010). Untuk kajian ini, perancangan pendokumentasian adalah berfokus bagaimana GPI merancang berasaskan dokumen kurikulum yang telah ditetapkan oleh KPM bagi mata pelajaran pendidikan Islam.

\subsubsection{Perancangan Komitmen}

Berdasarkan kajian ilmuan (Al-Kailani, Taisir \& Iyad Mulhim, 1986) terdapat tujuh panduan nilai kendiri atau pembentukan matlamat sebelum guru memulakan pengajaran iaitu (i) kaedah mestilah sesuai dengan objektif dan matlamat mata pelajaran yang di ajar (ii) kaedah hendaklah bersesuian dengan tabiat/asas pelajaran yang diajar (iii) kaedah mestilah sesuai dan setara dengan umur pelajar (iv) kaedah mestilah mampu dilaksanakan oleh guru (iv) masa yang mencukupi untuk mengaplikasi kaedah berkenaan dan (vii) kaedah yang dipilih mestilah bersesuaian dengan kemudahan yang ada. (Kamarul Azmi, Ab. Halim \& Mohd Izham, 2013) manakala (Mohd Aderi, 2008, 2012) mencadangkan agar guru memilih kaedah yang boleh memberi penghayatan yang mendalam, 
bukan sahaja kepada kefahaman pelajar, malah memberi kesan kepada jiwa pelajar. Kaedah ini mampu membantu pelajar memberi tumpuan, mengingat, mengekalkan ingatan dan mengaplikasikan dalam amalan seharian.

Menurut (Bahagian Pembangunan Kurikulum, Kementerian Pendidikan Malaysia, 2017), strategi perancangan pengajaran adalah untuk membina dan mengukuhkan minat pelajar-pelajar terhadap pembelajaran serta membimbing mereka supaya bersedia menerima pelajaran seterusnya dan berupaya pula meneruskannya sendiri

Berdasarkan takrifan di atas perancangan pengajaran bersifat komitmen ialah keupayaan guru untuk menganalisis pelaksanaannya terhadap semua aspek pengajaran dan pembelajaran. Ini termasuklah pemilihan dan pelaksanaan kaedah, teknik, aktiviti, bahan dan masa yang digunakan. (Robbins J.K, 2014) perancangan strategi yang digunakan seperti berpusatkan guru, berpusatkan pelajar, berpusatkan bahan atau gabungan daripada kesemua strategi ini. Untuk kajian ini, perancangan komitmen adalah berfokus nilai dan sikap GPI dalam merancang PdP pendidikan Islam berasaskan lingkaran kandungan yang telah ditetapkan oleh KPM.

\subsubsection{Perancangan Pelaksanaan}

Pelaksanaan perancangan yang berkesan menghasilkan pengajaran yang berkesan. Asas perancangan perlu mengambil kira semua aspek seperti sukatan pengajaran, kesediaan pelajar, tahap pengetahuan pelajar, suasana bilik darjah dan bahan bantu mengajar (BBM). Elemen ini membentuk proses pelaksanaan idea yang bersifat berstruktur dan dapat diterjemahkan dalam bentuk pengaplikasian. Kesemua idea pelaksanaan ini perlu dikategorikan mengikut asas komposisi pengajaran yang melibatkan elemen permulaan, perkembangan dan penutup (Caroline@Lorena \& Abdul Said, 2014). Untuk kajian ini, perancangan pelaksanaan adalah gerak kerja GPI di dalam memastikan perancangan yang telah ditetapkan oleh KPM bagi mata pelajaran pendidikan Islam bersumberkan sukatan.

\subsection{Pengintegrasian KBAT}

Pengintegrasian KBAT menurut (Brookhart, 2010) adalah menggabungkan dengan membentuk penyoalan, keupayaan, kefahaman dan penganalisaan sesuatu untuk memahami pemikiran sendiri dan orang lain. Di antara 
aktiviti yang boleh dijalankan untuk KBAT ini adalah melalui berfikir aktif, melihat konteks persekitaraan berdasarkan persepektif yang berbeza dan menyusun setiap idea dengan teratur (Sukiman Saad et al., 2013). Untuk kajian ini elemen-elemen yang terdapat dalam kemahiran pengintegrasian dalam melaksanakan KBAT seperti yang ditetapkan oleh dasar KPM seperti berikut:

\subsubsection{Kemahiran membuat kategori}

Kemahiran ini memerlukan keupayaan pelajar untuk membina kefahaman tentang perbezaan yang wujud dalam sesuatu kandungan seperti amalan ibadah yang dikategorikan ibadah atau yang dikategorikan adat. Maka menjadi keperluan kefahaman pelajar di isi dengan pengetahuan amalan ibadah dan adat seperti yang terdapat di dalam kandungan pengajaran (Zainuddin et al, 2005)

\subsubsection{Kemahiran menyusun mengikut urutan}

Penyusun mengikut urutan adalah kemahiran yang dijana menerusi pemikiran yang kritikal dan tersusun. Penyusunan ini melibatkan sama ada daripada abstrak kepada kejelasan, mudah kepada susah, khusus kepada umum dan keutamaan kepada kebiasaan. Penyusunan ini dilakukan dengan mengumpul keseluruhan kandungan isi penyusunan dan kemahiran ini memerlukan penganalisaan yang tinggi di dalam memastikan susunan yang dilakukan adalah bertepatan dengan struktur ilmu terbabit (N.S Ragendran, 2001; Zainuddin et al., 2005).

\subsubsection{Kemahiran membuat ramalan}

Kemahiran mengandaikan perkara yang dijangka berlaku daripada pendekatan yang kita gunakan adalah melalui terma-terma yang telah ditetapkan. Keupayaan untuk menjangka ini memerlukan menganalisis dan menilai keseluruhan item agar segala dapatan menuju kepada perkembangan yang sepatutnya. Kemampuan membuat ramalan mampu menjadi pembudayaan untuk menganalisis adalah sebahagian kerangka penerapan kepada para pelajar (Shahrom et al., 2008). 


\subsubsection{Kemahiran menjana idea}

Keupayaan pelajar untuk mengembangkan fakta yang di dapati berdasarkan pengetahuan yang disampaikan oleh guru. Proses penjanaan idea ini memerlukan penstrukturan dan panduan agar idea yang dikembangkan bertepatan dengan kehendak objektif yang dikendaki. Proses penjanaan idea memerlukan penguasaan kemahiran oleh guru melalui kefahaman berkaitan bagaimana idea yang seharusnya dikembangkan dan dihubungkait dengan idea yang lain (Wan Mat et al., 2011).

\subsubsection{Kemahiran mencipta definasi}

Keupayaan pelajar untuk mendefinasikan sesuatu perkara menandakan kefahaman yang ada pada pelajar. Definasi merupakan gambaran keseluruhan sesuatu kandungan ilmu yang menjadi kerangka untuk penghuraian seterusnya yang lebih mendalam. Guru bertanggungjawab membimbing pelajar untuk mempunyai kemahiran dalam pendefinasikan sesuatu kandungan ilmu walaupun setiap pelajar mungkin mempunyai kepelbagaian definasi tetapi selagi berada di dalam lingkungan ilmu tersebut, maka definisi harus diterima (Zainuddin et al, 2005; Wan Mat et al., 2011).

\subsubsection{Kemahiran mencipta analogi}

Proses kemahiran untuk mencipta perumpaan atau analogi memerlukan kefahaman yang sepenuhnya dalam kandungan ilmu kerana menghubung kaitkan kandungan ilmu dengan situasi semasa memerlukan keupayaan menganalisa dan mengaplikasi yang tinggi di kalangan pelajar. Ketidakmampuan untuk mencipta analogi menandakan penguasaan yang belum sepenuhnya berkaitan kemahiran berfikir aras tinggi (KBAT), maka guru perlu menerapkan kemahiran ini di dalam setiap pengajaran dan pembelajaran (PdP) yang di jalankan (Zainudin et al., 2005; Shahrom \& Nur Laili, 2008).

\subsection{Pendidikan Islam}

Matlamat Pendidikan Islam adalah untuk melahirkan murid yang berilmu, beriman, berketrampilan, beramal soleh dan berakhlak mulia berdasarkan 
Al Quran dan As Sunnah. Ia juga diharap akan melahirkan yang bertaqwa serta mampu menyumbang ke arah mempertingkatkan tamadun, bangsa dan negara (KPM, 2014).

Selaras dengan itu, sistem pendidikan kebangsaan telah memperkenalkan indikator atau dokumen standard kurikulum prestasi (DSKP) pengajaran pendidikan Islam sama ada yang melibatkan pelajar peringkat rendah dan menengah sebagai hala tuju yang perlu dicapai oleh semua pelajar. Elemen ini perlu diterjemahkan menerusi penekanan kepada kemahiran amali khususnya kemahiran berfokuskan untuk membentuk, keimanan, nilai kemanusiaan, kemasyarakatan dan kenegaraan. Hala tuju kurikulum pendidikan Islam yang merangkumi amalan pendidikan Asas Tilawah Al Quran, pembentukan akidah, bimbingan Fardhu Ain, pemupukan amalan Fardhu Kifayah dan amalan adab yang berteraskan Akhlak Islamiah (Bahagian Pendidikan Islam, KPM, 2014).

Untuk itu, menjadi kepentingan untuk guru bagi memastikan setiap pelajar dapat menguasai ilmu yang disampaikan supaya setiap daripada pelajar mampu membentuk diri menjadi muslim dan mukmin yang berilmu, beriman, berakhlak mulia, bertanggungjawab, beramal soleh dan bertaqwa selaras dengan falsafah, misi dan visi falsafah pendidikan Islam (Kamarul Azmi et al., 2010).

Maka di dalam proses pembentukan generasi yang berilmu, peranan utama yang harus dimainkan oleh guru adalah menerusi pedagogi pengajaran pendidikan Islam yang ingin disampaikan kepada pelajar dapat dipenuhi. Oleh itu sarjana-sarjana bidang pendidikan Islam seperti al-Qabisi dan Ibn Khaldun menjadi kerangka teori seterusnya membentuk garis panduan sebagaimana untuk memastikan pelaksanaan visi dan misi falsafah pendidikan Islam dapat dicapai. Mengikut (Dawud, 2001; Nik Mohd Rahimi et al., 2002; Sufian et al., 2005). Elemen seperti pengajaran berdasarkan tahap keupayaan pelajar, berperingkat, bersesuaian dengan konteks semasa dan menepati syariat oleh Allah swt merupakan komponen perhubungan yang dibentuk bersesuaian dengan pembelajaran abad ke 21. Oleh itu kajian ini telah mengklasifikasikan pendidikan Islam sebagai mata pelajaran yang terkandung di dalamnya al-Quran, jawi dan ulum syariah berasaskan dokumen yang ditentukan oleh KPM bagi peringkat sekolah rendah. 


\section{Metodologi Kajian}

Reka bentuk kajian ini merupakan kaedah tinjauan yang bersifat kuantitatif. Hasil dapatan kajian ini dilihat melalui bentuk perkiraan yang merangkumi nombor dan formula tertentu. Menurut (Creswell, 2009) kaedah tinjauan merupakan satu cara yang spesifik bagi mengumpul maklumat berkenaan sekumpulan besar populasi. Kaedah tinjauan ini menggunakan kaedah soal selidik bertujuan untuk melakukan penilaian yang melibatkan tiga komponen utama iaitu perancangan pendokumentasian, perancangan komitmen dan perancangan pelaksanaan. Kajian ini menggunakan instrument soal selidik dan kaedah pengukuran berdasarkan ujian analisis deskriptif iaitu min bagi menentukan ciri-ciri pembolehubah tanpa melakukan generilisasi.

Populasi kajian ini melibatkan guru-guru pendidikan Islam (GPI) bagi peringkat sekolah rendah di Malaysia yang berjumlah 402 orang dengan pembahagian taburan kajian menggunakan 5 zon iaitu melibatkan Zon Utara, Zon Tengah, Zon Timur, Zon Selatan dan Zon Malaysia Timur. Jumlah keseluruhan GPI di Malaysia adalah 38,502 orang berdasarkan maklumat daripada (Bahagian Perancangan dan Penyelidikan Dasar Pendidikan, Kementerian Pendidikan Malaysia,2015) namun berdasarkan jadual (Krajie \& Morgan, 1970, Mohd Majid, 2005; Cohen, 2007) menerusi penentuan sampel daripada populasi jumlah yang bersesuian ditetapkan 382 orang. Untuk itu kajian ini menggunakan 402 orang GPI sebagai sampel dengan justifikasi kemungkinan terdapat sampel yang tidak memulangkan instrumen yang dibekalkan dan ini menganggu analisis yang dijalankan (Cohen, 2011). GPI yang terpilih adalah ditentukan berdasarkan pengkategorian mengikut jantina, kelayakan akademik, umur dan pengalaman mengajar.

Kajian ini telah mengadaptasikan instrumen Amalan pengajaran guru oleh Aderi Che Noh, Asas taksonomi yang dibangunkan oleh Bloom dan Anderson, Pelan Pembangunan Pendidikan Malaysia 2013-2025 (elemen pedagogi) dan dasar pelaksanaan KBAT melalui instrumen pengajaran KBAT GPI. Instrumen yang dibina ini distrukturkan kepada empat bahagian iaitu bahagian A berkaitan demografi, bahagian B mengandungi perancangan komitmen, bahagian $\mathrm{C}$ mengandungi perancangan pendokumensian dan bahagian $\mathrm{D}$ mengandungi perancangan pelaksanaan.

Proses kesahan instrumen menggunakan semakan pakar yang melibatkan tiga pakar daripada bidang pendidikan Islam dan metodologi kajian. Pakar ini terdiri daripada pensyarah universiti dan institut 
pendidikan guru. Hasil semakan pakar ini, beberapa item perlu distrukturkan semula agar ianya lebih berfokuskan untuk menjawab objektif kajian. Sebelum kajian sebenar dijalankan, kajian rintis telah dilaksanakan iaitu di daerah Manjung yang melibatkan 30 orang guru GPI. Keperluan memilih daerah Manjung adalah keadaan demografinya yang mempunyai kategori sekolah bandar, luar bandar dan pulau. Ini menepati pengkategorian sekolah-sekolah rendah di seluruh Malaysia. Setelah kajian rintis dijalankan, analisis kebolehpercayaan dilaksanakan dan dapatan memperlihatkan item bagi setiap konstruk berada pada tahap tinggi iaitu nilai Alpha Cronbach mencatatkan (0.82173).

Jadual 1 menunjukkan bagi nilai kebolehpercayaan melibatkan komponen perancangan pendokumentasian yang mencatatkan (0.8905), komponen perancangan komitmen (0.7727) dan komponen perancangan pelaksanaan yang mencatatkan $(0.8020)$.

\section{Jadual 1: Nilai Pekali Kebolehpercayaan Instrumen Soal Selidik}

\begin{tabular}{ll}
\hline Pembolehubah & Nilai Alpha Cronbach \\
\hline & \\
Perancangan komitmen & 0.7727 \\
Perancangan pendokumentasian & 0.8905 \\
Perancangan pelaksanaan & 0.8020 \\
& $\mathbf{0 . 8 2 1 7 3}$ \\
\hline
\end{tabular}

Skala Likert lima mata digunakan dalam kajian ini. Kaedah skor yang digunakan ialah Sangat Tidak Setuju (STS) dengan skor 1 mata, Tidak Setuju (TS) dengan skor 2 mata, Kurang Pasti (KP) dengan skor 3 mata, Setuju (S) dengan skor 4 mata dan Sangat Setuju (SS) dengan skor 5 mata. Data yang diperolehi ini di analisis mengunakan statistik deskriptif yang melibatkan kekerapan, peratusan dan min.

Dapatan data dikumpulkan melibatkan tempoh masa selama lima bulan dengan pengkategorian sampel mengikut pensampelan berkelompok dan berstrata. Penyelidikan memulakan kajian di negeri kedah bagi zon utara, negeri Selangor bagi zon tengah, Melaka bagi zon selatan, Terengganu bagi zon timur dan Sarawak bagi zon Malaysia timur

Kesemua item ini dianalisis dan diubahsuai oleh penyelidik agar menepati objektif dan persoalan kajian. Kajian ini menganalisis dengan 
menggunakan Statistical Package for the Social Sciences (SPSS) versi 20.0 dan diringkaskan menerusi jadual tiga berdasarkan nilaian frekuensi dan peratus untuk jantina, umur, taraf pendidikan, pengalaman mengajar GPI dalam pelaksanaan KBAT pendidikan Islam (Mohd Majid, 2005; Pallant, 2010).

Jadual 2: Analisis frekuensi dan peratus untuk jantina, taraf pendidikan, pengalaman mengajar berdasarkan GPI

\begin{tabular}{lcc}
\hline Pemboleh Ubah & Frekuensi & Peratus \\
\hline Jantina & 146 & \\
1)Lelaki & 256 & 36.31 \\
2) Perempuan & & 63.69 \\
& & \\
Taraf Pendidikan & 155 & 38.55 \\
2) Diploma & 193 & 48.00 \\
3) Sarjana Muda & 54 & 13.45 \\
4) Sarjana & & \\
Pengalaman Mengajar & 113 & 28.10 \\
1) Kurang 3 tahun & 142 & 35.32 \\
2) 4- 10 tahun & 147 & \\
3) 10 tahun ke atas & & \\
\hline
\end{tabular}

Berdasarkan jadual ini, taburan jantina bagi guru yang terlibat dalam kajian ini adalah terdiri daripada 146 lelaki dan 256 perempuan. Ini menunjukkan kebanyakan guru yang terlibat adalah guru perempuan yang sememangnya mendominasi perjawatan di dalam bidang perguruan ini. Guru-guru ini adalah berkemampuan dan bersifat produktif di dalam menyumbang kepada perancangan pengajaran yang berkesan dan berteraskan KBAT. Bagi kategori taraf pendidikan, di dapati ramai guru yang berada pada tahun diploma dan sedang melanjutkan pengajian bagi peringkat ijazah, ini membuktikan guru mempunyai komitmen meningkatkan pengetahuan berkaitan pendekatan pengajaran yang berkesan dan ini merupakan salah satu daripada elemen di dalam pelaksanaan KBAT iaitu guru berpengetahuan. Bagi kategori taraf pendidikan ini, di dapati guru yang mempunyai diploma adalah seramai 
155 orang, di ikuti Ijazah sarjana muda seramai 193 orang dan peringkat sarjana seramai 54 orang.

Untuk kategori pengalaman mengajar di dapati guru yang terlibat dalam kajian ini adalah terdiri daripada guru yang mempunyai pengalaman mengajar melebihi 10 tahun iaitu seramai 147 orang dan ini mengambarkan tidak akan wujud permasalahan dalam pelaksanaan KBAT ini disebabkan mempunyai asas pengajaran yang mampu dalam mempelbagaikan kaedah yang dapat menarik perhatian pelajar. Bagi kategori pengalaman mengajar ini, guru yang kurang daripada 3 tahun adalah seramai 113 orang dan 4 hingga 10 tahun seramai 142 orang.

\section{Dapatan Kajian}

Huraian berdasarkan analisis deskriptif iaitu min serta gambaran setiap item kajian.

\section{Jadual 3: Dapatan Keseluruhan Kajian}

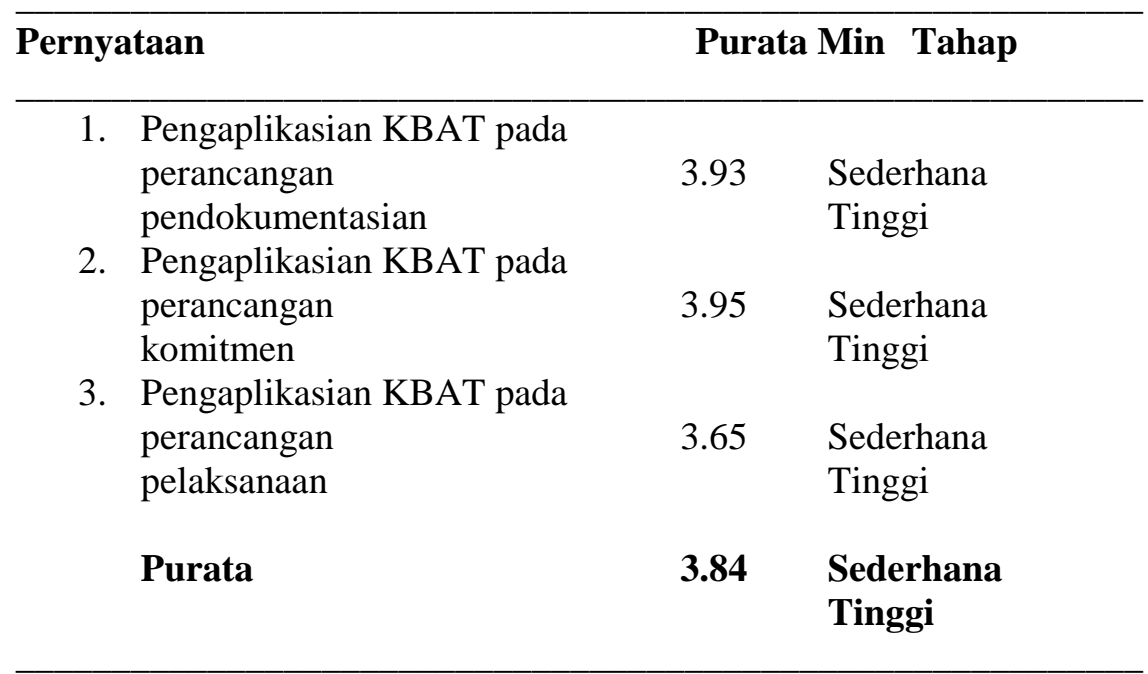

\subsection{Perbincangan}

Perbincangan berkaitan hasil dapatan kajian adalah berdasarkan komponen perancangan pengajaran yang terdiri daripada perancangan komitmen, perancangan pemdokumentasian dan perancangan pelaksanaan. 


\subsubsection{Dapatan Kajian Perancangan Pendokumentasian}

Perbincangan dapatan kajian bagi konstruk itu berfokuskan untuk menjawab objektif kajian yang pertama iaitu untuk mengenalpasti perancangan pendokumentasian pengajaran guru berdasarkan KBAT dalam mata pelajaran pendidikan Islam sekolah rendah.

Pengkaji mendapati pengaplikasian KBAT dalam mata pelajaran pendidikan Islam di kalangan guru-guru sekolah rendah di pada perancangan pendokumentasian berada pada tahap sederhana tinggi dengan purata min (3.93). Berdasarkan dapatan kajian bagi item yang mencatatkan peratusan min yang tertinggi adalah guru sentiasa menetapkan menulis perancangan di dalam rancangan pengajaran harian $(\mathrm{RPH})$ berdasarkan analisis yang dilakukan terhadap tajuk yang telah di ajarkan sebelum. Ini membuktikan guru sentiasa mengambil berat elemen perancangan yang akan ditetapkan seharusnya berdasarkan tahap keupayaan pelajar yang di dapati daripada pencapaian pembelajaran sebelumnya. Ini menepati kajian oleh (Siti Marlina, 2013) yang menyatakan elemen pemikiran perlu dititikberatkan dalam menentukan perancangan yang bersesuian.

Walau bagaimana pun, item berkaitan konsisten amalan pendokumentasian dilaksanakan secara mingguan telah mencatatkan nilai min yang rendah. Ini disebabkan kekangan masa di kalangan guru yang terlibat dengan pelbagai aktiviti terutamanya pada awal tahun. Kebiasaan guru mendokumentasi segala perkara berkaitan PdP adalah berdasarkan keadaan dan kesesuian masa. Untuk itu, penambahbaikan yang perlu dijalankan adalah berkaitan guru berinteraksi dengan pelajar berkaitan mendokumentasikan pendekatan PdP yang digunakan dalam pengajaran. Keadaan ini disumbangkan peruntukan masa yang terhad, maka harus dipastikan segala aktiviti yang perlu dilaksanakan adalah mampu dilaksanakan. Ini selari dengan keperluan (KPM, 2014) yang menetapkan struktur masa adalah keperluan dalam menghasilkan perancangan yang berkualiti Dari segi keseluruhannya, kajian ini mendapati wujud pengamalan yang sederhana tinggi di dalam amalan perancangan pendokumentasian di kalangan GPI.

\subsubsection{Dapatan Kajian Perancangan Komitmen}

Perbincangan dapatan kajian bagi konstruk itu berfokuskan untuk menjawab objektif kajian yang kedua iaitu untuk mengenalpasti 
perancangan komitmen guru berdasarkan KBAT dalam mata pelajaran pendidikan Islam sekolah rendah.

Dapatan menunjukkan guru-guru mengaplikasikan KBAT pada peringkat perancangan komitmen berada pada tahap yang sederhana tinggi dengan purata min (3.95). Penghasilan aktiviti yang mencatatkan peratusan min yang tertinggi adalah guru merancang aktiviti menerusi kefahaman pelajar dengan tertakluk kepada sukatan yang telah ditetapkan. Ini membuktikan guru menggunakan objektif yang jelas untuk melaksanakan perancangan untuk meningkatkan keupayaan pelajar melalui aktiviti seperti kerja kumpulan, kajian mata pelajaran, mengikut tahap kesesuian pelajar dan kemahiran pelajar menganalisis sesuatu topik yang di ajar. Dapatan ini menepati kajian yang menyatakan terdapat tujuh panduan nilai kendiri atau pembentukan matlamat sebelum guru memulakan pengajaran (Al-Kailani, Taisir \& Iyad Mulhim, 1986).

Namun untuk menghasilkan perancangan aktiviti yang teliti dan jelas berasaskan pengaplikasikan elemen KBAT memerlukan faktor pengetahuan, kemahiran dan persediaan yang mencukupi di kalangan GPI. Oleh itu, penambahbaikan yang perlu dijalankan adalah berkaitan guru memberi masa kepada pelajar untuk memahami falsafah disebalik aktiviti yang ditetapkan, ini pendekatan yang sukar dilaksanakan di peringkat sekolah rendah kerana tahap kemampuan memahami konsep sesuatu aktiviti berada pada tahap rendah dan memerlukan perancangan bimbingan yang berterusan oleh guru di dalam memastikan pelajar memahami apa tujuan sesuatu tajuk itu di sampaikan

\subsubsection{Dapatan Kajian Perancangan Pelaksanaan}

Perbincangan dapatan kajian bagi konstruk itu berfokuskan untuk menjawab objektif kajian yang ketiga iaitu untuk mengenalpasti perancangan pelaksanaan berdasarkan KBAT dalam mata pelajaran pendidikan Islam sekolah rendah.

Guru-guru mengaplikasikan KBAT pada peringkat pelaksanaan berada pada tahap yang sederhana dengan purata min (3.65). Berdasarkan dapatan kajian bagi perancangan pelaksanaan ini mencatatkan peratusan min yang tertinggi adalah guru melakukan perancangan berkaitan apa yang telah dirancang menerusi kefahaman yang jelas perkaitan dengan tajuk yang akan di ajar. Ini membuktikan bahawa guru memberi kebebasan kepada pelajar untuk melakukan pengaplikasian dan pelaksanaan berdasarkan tahap kefahaman, keupayaan dan kemampuan pelajar (Caroline@Lorena \& Abdul Said, 2014). 
Namun kajian mendapati, masih terdapat guru merancang pelaksanaan pengajaran hanya bertujuan untuk peperiksaan sahaja bukannya untuk penguasaan ilmu kerana guru terikat dengan sukatan yang ditetapkan. Selain itu perancangan pelaksanaan adalah berdasarkan keupayaan pelajar yang memerlukan pertimbangan yang menyeluruh dari aspek pengetahuan, matlamat dan kaedah melaksanakannya. Oleh itu, penyelesaian kepada permasalahan ini memerlukan untuk guru merancang pelaksanaan KBAT yang berpusatkan pelajar dan pelajar didedahkan dengan gambaran keseluruhan bagaimana proses PdP KBAT dapat dilaksanakan. Ini bermatlamatkan kefahaman GPI di dalam melaksanakan perancangan PdP KBAT dapat dijadikan sebagai suatu amalan yang konsisten.

Secara keseluruhannya berdasarkan tinjauan awal mendapati pengamalan yang sederhana tinggi di dalam pelaksanaan perancangan mata pelajaran pendidikan Islam mengintegrasikan KBAT di kalangan GPI di Malaysia.

\subsubsection{Dapatan Kajian Keseluruhan}

Dapatan keseluruhan menunjukkan penerapan perancangan KBAT sememangnya berlaku di dalam pelaksanaan pengajaran GPI namun beberapa penambahbaikan perlu dilakukan seperti keperluan menetapkan proses interaksi pelajar sesama pelajar bagi mendapatkan input apa perancangan yang diperlukan. Selain itu, keperluan mengadakan sesi perbincangan di kalangan pelajar dan guru dengan bersumberkan ketetapan objektif seperti yang dihasratkan oleh Kementerian Pendidikan Malaysia (KPM). Seterusnya beberapa cadangan penambahbaikan di peringkat perancangan pendokumentasian, komitmen dan pelaksanaan seharusnya menekankan kepada aspek-aspek yang berikut iaitu asas perancangan perlu menitikberatkan penghasilan daripada proses $\mathrm{PdP}$ KBAT secara berterusan dan meliputi keseluruhan pengajaran.

Kajian ini juga memperlihatkan kepelbagaian perancangan berteraskan aktiviti-aktiviti yang dijalankan hendaklah berteraskan objektif pengajaran dan elemen penyoalan. Pendekatan ini memerlukan peningkatan serta dipelbagaikan agar proses pelaksanaan KBAT dapat diterapkan secara sepenuhnya. Semua persolan yang dilaksanakan semasa perancangan pengajaran ini merupakan asas permulaan kepada KBAT seiring dengan dapatan yang diperolehi. 


\section{Kesimpulan}

Untuk keseluruhannya dapatan ini mengukuhkan dan memantapkan bagaimana perancangan yang berkesan berasaskan isi kandungan pengajaran guru. Penelitian yang jelas mengenai pelaksanaan perancangan pengajaran KBAT dalam pendidikan Islam memerlukan menfokuskan kepada terma-terma penting di dalam elemen pemikiran KBAT serta beberapa persoalan-persoalan baru di dalam memantapkan kefahaman pelajar tentang kepentingan memahami, menganalisis dan menghayati amalan beragama di dalam kehidupan seharian

\section{Rujukan}

Al-Quran.

Ab Halim Tamuri \& Mohammad Khairul Azman AJuhary. (2010). Amalan pengajaran guru Pendidikan Islam berkesan berteraskan konsep "muallim". Journal Islamic and Arabic Education 2(1) 43-56.

Ab. Halim Tamuri \& Nik Mohd. Rahimi Nik Yusoff. (2012). Kaedah Pengajaran dan Pembelajaran Pendidikan Islam. Kuala Lumpur: Percetakan Watan Sdn. Bhd.

Abdullah Nasih Ulwan (2002), Pendidikan Anak-anak Dalam Islam.Syed Ahmad Semait (terj.) Singapura: Pustaka Nasional Pte.Ltd.

Abd Karim Zaidan. (2006). Al-Wajiz fil Usul Fiqh. Lebanon: Resalah Publishers.

Al-Kailani, Taisir \& Iyad Mulhim. (1986). At-taujih, al-fanny fi usul tarbiyah wa tadris. Beirut. Maktabah Lubnan

Al-Qabisi, Abu Hassan Ali Muhammad Khalaf. (1955). Al-risalah almufassalah lilahwal al-muta'alimin wa ahkam wa muta'alimin. Kaherah: Dar Ehya' al-Kutub al-Arabiyyah.

Al-Shāfi'i, Hasan Muhammad. (2010). Lamhāt Min al-Fikr al-Kalāmī. Qahirah: Dar al-Basair.

Amabile M, Hennessey A, Beth. \& Teressa. (2010). Creativity. Annual Review of Psychology; 61, 569-598.

Asmawati Suhid, \& Fathiyah Mohd Fakhruddin , (2012) Gagasan pemikiran falsafah dalam pendidikan Islam: hala tuju dan cabaran. JIAE: Journal of Islamic and Arabic Education, 2 (4). pp. 57-70. ISSN 1985-6236. 
Azhar Ahmad. (2006). Strategi pembelajaran pengaturan kendiri pendidikan Islam dan penghayatan akhlak pelajar sekolah menengah. Tesis Ph.D. Fakulti Pendidikan, Universiti Kebangsaan Malaysia.

Bahagian Pembangunan Kurikulum. (2017). Dokumen Standard Kurikulum dan Pentaksiran Pendidikan Islam Tahun Empat dan Lima. Putrajaya: Kementerian Pendidikan Malaysia.

Bahagian Pendidikan Islam. (2014). Modul Pengajaran Pendidikan Islam Sekolah Rendah. Putrajaya: Kementerian Pendidikan Malaysia.

Bahagian Perancangan dan Penyelidikan Dasar Pendidikan. (2015). Unjuran guru di Malaysia (Laporan Pelan Pembangunan Pendidikan di Malaysia). Putrajaya; Kementerian Pelajaran Malaysia.

Boaler, J. (2008). Promoting relational equity' and high mathematics achievement through an innovative mixed ability approach. British Educational Research Journal. 34 (2), 167-194

Brookhart, S. (2010). How to Assess Higher Order Thinking Skills in Your Classroom, ASCD.

Caroline@Lorena David \& Abdul Said Ambotang (2014). Profesionalisme guru novis dalam pengurusan pengetahuan, kesediaan mengajar dan kemahiran berfikir aras tinggi terhadap pelaksanaan pengajaran di sekolah. Kota Kinabalu: Universiti Malaysia Sabah.

Cohen, J. Lawrence Manion \& Keith Marrison (2007). Research Method in Educatio. London; Routledge, Francais and Taylor Group.

Creswell, J. W. (2009). Educational research: Planning, conducting, and evaluating quanitative and qualitative research. Upper Saddle River, New Jersey: Pearson Education, Inc.

Dawud Tawhidi. (2001). An Overview. Towards A Renewal Vision of Islamic Education. Pages 8, The Tarbiyah Project.

Ibn Khaldun. (1993). Muqaddimah Ibn Khaldun. (Terj.). Kuala Lumpur: Dewan Bahasa dan Pustaka.

J. Pallant. (2010). SPSS Survival Manual a Step by Step Guide to Data Analysis using SPSS for Windows, $4^{\text {rd }}$ Edition, Crows West, New South Wales.

Kamarul Azmi Jasmi, Ab. Halim Tamuri, \& Mohd Izham Mohd Hamzah. (2010). Faktor pentadbir dan pengetua dalam kecemerlangan guru cemerlang Pendidikan Islam dan guru di sekolah menengah: satu kajian kes. JIAE: Journal of Islamic and Arabic Education, 2(1). pp. 13-20. ISSN 1985-6236. 
Kementerian Pendidikan Malaysia. (2014). Buku dasar elemen kemahiran berfikir aras tinggi (Kurikulum). Putrajaya: Bahagian Pembangunan Kurikulum.

Kementerian Pendidikan Malaysia. (2014). Buku dasar elemen kemahiran berfikir aras tinggi (Pedagogi). Putrajaya: Bahagian Pembangunan Kurikulum.

Kementerian Pendidikan Malaysia. (2014). Buku dasar elemen kemahiran berfikir aras tinggi (Pentaksiran). Putrajaya: Bahagian Pembangunan Kurikulum.

Khairiah Razali, (2013). Kemahiran Berfikir Aras Tinggi dalam Pendidikan Islam. Batu Pahat. Kementerian Pendidikan Malaysia.

Khalid, T. (2010). An integrated inquiry activity in an elementary teaching methods classroom. Science Activities: Classroom projects and curriculum ideas.

Krejcic, R.V \& Morgan, D.W. (1970). Determining sample saiz for research activities, education and psychogical measurement, 30: 608-619.

Mohd Aderi Che Noh. (2008). Hubungan antara amalan pengajaran guru dan pencapaian tilawah al-Quran pelajar tingkatan dua di Malaysia. Tesis Ph.D. Fakulti Pengajian Pendidikan: Universiti Putra Malaysia.

Mohd Aderi Che Noh. (2012). Pelaksanaan kelas kemahiran al-Quran di Malaysia: satu analisis. Journal of Islamic and Arabic Educatin, 3(1), 47-58.

Mohd Majid Konting. (2005). Kaedah penyelidikan pendidikan. Kuala Lumpur: Dewan Bahasa dan Pustaka.

Mohd Fauzi Hamat \& Mohd Khairul Naim Che Nordin. (2012), Akidah dan Pembangunan Modal Insan. Kuala Lumpur: Penerbit Universiti Malaya.

Nik Mohd Rahimi Nik Yusof, Shahrin Awaluddin, Khadijah Abdul Razak, Ab Halim Tamuri, Mohd Isa Hamzah \& Kamarulzaman Abd Ghani. (2002). Kurikulum Pendidikan Islam Menghadapi Cabaran Era Globalisasi dalam Prosiding Wacana Pendidikan Islam (Siri 1). Fakulti Pendidikan, Universiti Kebangsaan Malaysia.

Noor Hisham Md Nawi. (2011). Pengajaran dan pembelajaran: penelitian semula konsep-konsep asas menurut perspektif gagasan Islamisasi ilmu moden. Kongres pengajaran dan pembelajaran; Universiti Kebangsaan Malaysia. 
Partnership for 21st Century Skills. (2010). Beyond the Three Rs: Voter Attitudes Toward 21st Century Skills. Tucson, AZ.

Rajendran, Nagappan. (2001). Teaching higher-order thinking skills in language classrooms: The need for transformation of teaching practice. Paper presented at the $9^{\text {th }}$ International Conference on Thinking, Auckland, New Zealand.

Robert Glaser. (1983). Cognitive and motivational aspects of instruction: selected International Congress papers. Amsterdam: Elsevier.

Robbins, Joanne. (2014). Learn to reason with TAPS: A talk aloud problem solving approach. Seattle, Washington DC: Robbins/Layng \& Associates.

Rosnani Hashim. (2012). Rethinking islamic education in facing the challenges of the twenty-first century. American Journal of Islamic Social Sciences, 22(4): 133-147.

Saavedra, A. \& Opfer, V. (2012). Learning 21st-century skills requires 21 st-century teaching. Phi Delta Kappan, 94(2), 8-13.

Sarmah Mokhtar, Ab Halim Tamuri, Mohd Aderi Che Noh, Nurul Huda Hassan, Mohamad Maliki Ali, Mohd Kashfi Mohd Jailani, Zahiah Haris@ Harith \& Mustafa Kamal Ahmad Kassim. (2011). Kajian persepsi pelajar terhadap personaliti dan amalan pengajaran guru pendidikan Islam sekolah menengah di Selangor. Prosiding penyelidikan international conference and exhibition on research Islamic and Arabic language education. Bangi: Association of Malaysian Muslim Intellectual.

Sidek Baba. (2010). Kehidupan Sejahtera Terbina Atas Pendidikan Bersepadu. Pendidik Bilangan 73.

Sidek Baba. (2011). Tajdid Ilmu Dan Pendidikan. Selangor: Gemilang Press Sdn. Bhd.

Siti Marlina Sabran. (2013). Kemahiran Berfikir Aras Tinggi (KBAT) pelajar tingkatan lima dalam penyelesaian matematik. Johor Bharu: Universiti Teknologi Malaysia.

Shaharom Noordin \& Nur Laili Lockman. (2008). Tahap Penguasaan Kemahiran Meramal Dan Kemahiran Mengawal Pembolehubah Dalam Kalangan Pelajar Pendidikan Kimia. Skudai, Fakulti Pendidikan: Universiti Teknologi Malaysia.

Sufean Hussin, Shahril Marzuki, Ahmad Zabidi, Habib Md Som dan Alina Ranee. (2005). Pentadbiran dalam Pembangunan Pendidikan. Pahang: PTS Profesional Publishing Sdn Bhd

Sukiman Saad, Noor Shah Saad \& Mohd Uzi Dollah. (2013): Pengajaran kemahiran berfikir: persepsi dan amalan guru matematik semasa 
pengajaran dan pembelajaran di bilik darjah: Jurnal Pendidikan Sains dan Matematik Malaysia, Tanjung Malim; Universiti Pendidikan Sultan Idris.

Wan Hassan Wan Embong, Sulaiman Shakib Mohd Noor, Zulkiflee Haron \& Mohd Nasir Ripin. (2013). Penggunaan BBM dalam pendidikan akidah: kajian kes guru cemerlang pendidikan Islam. Proceeding of SIST, Yogyakarta: Indonesia.

Wan Mat Sulaiman \& Hjh Norkhairiah Pg Hj Hashim. (2011). Aplikasi kemahiran berfikir dalam pengajaran Pengetahuan Agama Islam. Journal of Applied Research in Education, Vol 15, No.1 \& 2, pp.43-58.

Zaharah Hussin. (2005). Keperluan pendidikan akhlak dalam latihan perguruan pendidikan Islam latihan perguruan. (The needs of akhlak education in Islamic Education teacher training) Dlm: Pentadbiran dalam Pembangunan Pendidikan. Bentong: PTS Publication.

Zainudin Hassan, Hamdan Said, Jamilah Omar \& Haslita Hassan. (2005). Pengaplikasian kemahiran berfikir dalam pengajaran kemahiran hidup bersepadu di sekolah menengah daerah kota bahru, Kelantan. Johor Bharu: Universiti Teknologi Malaysia.

Zuraidah Ramdzan@Ramban. (2013). Kesediaan, amalan dan strategi pengajaran pendidikan Islam Kurikulum Standard. Skudai. Universiti Teknologi Malaysia. 